\title{
What is the research evidence for antibiotic resistance exposure and transmission to humans from the environment? A systematic map protocol
}

\author{
Isobel C. Stanton ${ }^{1 \dagger}$, Alison Bethel ${ }^{2 \dagger}$, Anne F. C. Leonard ${ }^{1}$, William H. Gaze ${ }^{1}$ and Ruth Garside ${ }^{3^{*}}$ (D)
}

\begin{abstract}
Background: Antimicrobial resistance (AMR) is a public health crisis that is predicted to cause 10 million deaths per year by 2050. The environment has been implicated as a reservoir of AMR and is suggested to play a role in the dissemination of antibiotic resistance genes (ARGs). Currently, most research has focused on measuring concentrations of antibiotics and characterising the abundance and diversity of ARGs and antibiotic resistant bacteria (ARB) in the environment. To date, there has been limited empirical research on whether humans are exposed to this, and whether exposure can lead to measureable impacts on human health. Therefore, the objective of this work is to produce two linked systematic maps to investigate previous research on exposure and transmission of AMR to humans from the environment. The first map will investigate the available research relating to exposure and transmission of ARB/ARGs from the environment to humans on a global scale and the second will investigate the prevalence of ARB/ARGs in various environments in the UK. These two maps will be useful for policy makers and research funders to identify where there are significant gluts and gaps in the current research, and where more primary and synthesis research needs to be undertaken.

Methods: Separate search strategies will be developed for the two maps. Searches will be run in 13 databases, and grey literature will be sought from key websites and engagement with experts. Hits will be managed in EndNote and screened in two stages (title/abstract then full text) against predefined inclusion criteria. A minimum of 10\% will be double screened with ongoing consistency checking. All included studies will have data extracted into a bespoke form designed and piloted for each map. Data to be extracted will include bibliographic details, study design, location, exposure source, exposure route, health outcome (Map 1); and prevalence/percentage of ARB/ARG (Map 2). No validity appraisal will be undertaken. Results will be tabulated and presented narratively, together with graphics showing the types and areas of research that has been undertaken and heatmaps for key exposure-health outcomes (Map 1) and exposure-prevalence (Map 2).
\end{abstract}

Keywords: Antibiotic resistance, Health, Colonisation, Infection, Water, Air, Soil, Faeces, Food

*Correspondence: R.Garside@exeter.ac.uk

${ }^{\dagger}$ Isobel C. Stanton and Alison Bethel_Joint first authors

${ }^{3}$ European Centre for Environment and Human Health, College

of Medicine and Health, Knowledge Spa, University of Exeter, Truro TR1 3HD, UK

Full list of author information is available at the end of the article

\section{Background}

Antibiotics are antimicrobials used to prevent and treat bacterial infections. Their efficacy is important as their use is critical in human and veterinary medicine, as well as in food production practices [1]. Presently, the efficacy of antibiotics is being undermined by the ability of

c) The Author(s) 2020. This article is licensed under a Creative Commons Attribution 4.0 International License, which permits use, sharing, adaptation, distribution and reproduction in any medium or format, as long as you give appropriate credit to the original author(s) and the source, provide a link to the Creative Commons licence, and indicate if changes were made. The images or other third party material in this article are included in the article's Creative Commons licence, unless indicated otherwise in a credit line to the material. If material is not included in the article's Creative Commons licence and your intended use is not permitted by statutory regulation or exceeds the permitted use, you will need to obtain permission directly from the copyright holder. To view a copy of this licence, visit http://creativeco mmons.org/licenses/by/4.0/. The Creative Commons Public Domain Dedication waiver (http://creativecommons.org/publicdomain/ zero/1.0/) applies to the data made available in this article, unless otherwise stated in a credit line to the data. 
bacteria to resist the actions of these drugs (antibiotic resistance). This results in treatment failure, prolonged morbidity and increased risk of mortality when treating infections caused by resistant pathogens [2]. The devastating impact of such resistance has led to antibiotic resistance and antimicrobial resistance (AMR) more broadly, being placed on the UK Risk Register, alongside other critical risks such as climate change, pandemic influenza and global terrorism [3, 4]. It has been predicted that by 2050 AMR will be the leading cause of death globally, accounting for 10 million deaths per year [2]. The term AMR includes resistance to agents with antimicrobial properties by microorganisms, such as bacterial, fungal, viral or parasitic organisms. It is frequently used interchangeably in the literature with the term antibiotic resistance. However, the focus of this study will be antibiotic resistant bacteria (ARB).

The occurrence of infections that are resistant to antimicrobials is increasing globally $[1,5,6]$. Successful treatment of resistant bacterial infections increasingly relies on more expensive "last-resort" antibiotics. Resistance has, however, already developed to such antibiotics, for example, colistin [7]. In addition, there are few novel antimicrobials being discovered and coming to market, as the investment (in time and money) needed to develop these drugs is high and as small returns is promised in the lifetime of the patent [8]. In the last three decades, only two antibiotic classes, oxazolidinones and cyclic lipopeptides, have been brought to market [9]. Without the discovery of new antibiotics, and with the development of resistance, it is possible that we will enter an era similar to that before the discovery of antibiotics, where routine medical procedures become far riskier as a result of our inability to prevent or treat infections which are currently simple to treat [10].

The 2014 O'Neill report, commissioned by the UK government, stated that the global number of deaths annually from AMR will increase from 700,000 in 2014 to 10 million by 2050 . This report also predicted that AMR will negatively impact the global economy, estimating a drop in the world's GDP of $2.5 \%$ to $3 \%$ (up to 100 trillion US dollars) between 2014 and 2050 as a consequence of AMR [2]. In the UK, the Chief Medical Officer stated that AMR infections already cost the NHS approximately $£ 180$ million every year [11].

There is a vast range of research that has been undertaken investigating the impact of AMR from a clinical perspective [12-17]. However, the role of the environment in the dissemination of AMR is only recently being investigated. Human use of antibiotics has been implicated in the rise of resistance, with our activities accelerating the development and dissemination of antibiotic resistance genes (ARGs) in and to the environment. In
2017, the United Nations Environment Programme Frontiers report highlighted AMR as the most critical emerging environmental pollution issue [18]. Although AMR is an ancient and natural phenomenon [19], the increased use of compounds with antimicrobial properties and their subsequent release into the environment through anthropogenic activities has increased the rate of the development of novel resistance and dissemination in such compartments [20]. For example, a large proportion (up to 90\% [21]) of administered antibiotic is excreted in its biologically active form in both urine and faeces from treated patients and animals and this can be released into receiving environments such as soil and water [12] in concentrations that range from $n g / L$ to $\mu \mathrm{g} / \mathrm{L}$ [22]. Research has shown that these environmentally relevant concentrations of antibiotics are able to select for ARGs [23-27]. As a result of both naturally occurring ARGs, and selective pressure from antimicrobial compounds used by humans, research has found that ARGs are found ubiquitously throughout environmental compartments [20]. Furthermore, there is evidence that ARGs in environmental bacteria have the potential to be taken up by human-associated bacteria and pathogenic bacteria via horizontal gene transfer [28, 29], and that people exposed to AMR in the environment are at greater risk of being faecal carriers of AMR compared to people with less exposure [30].

This topic area has been previously mapped to the Driver-Pressure-State-Exposure-Effect-Action (DPSEEA) Framework [31]. The basic DPSEEA Framework can be seen in Fig. 1.

For environmental AMR research: "Driver" may refer to increasing number of resistant infection; "Pressure" may refer to inappropriate disposal of antimicrobials or other co-selecting agents into the environment; "State" may refer to the concentration levels of antimicrobials in the environment or abundance of resistant organisms or genes; "Exposure" may refer to direct contact with the environment resulting in inhalation or consumption of resistant organisms or genes; "Effect" may refer to the human health outcome of this exposure and "Action" may refer to any action taken at any stage of this framework to mitigate the human health outcome.

The majority of the research undertaken investigating AMR in the environment has focused on identifying

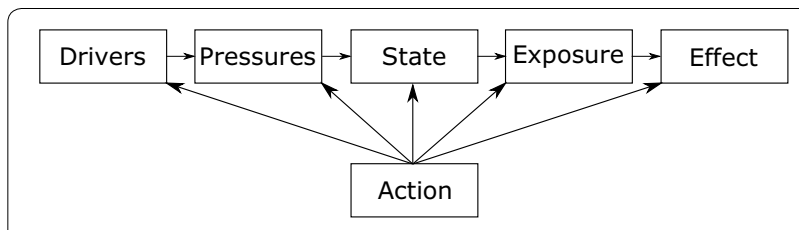

Fig. 1 DPSEEA Framework adapted from Morris et al. [32] 
and quantifying the discharge of various chemical and microbial pollutants (Pressure and State), including the concentrations of antimicrobials [33-35], ARB [36-38] and ARGs [39-41] in the environment. However, there is limited data on the fate of these pollutants (Exposure and Effect). The question of whether AMR levels in the environment are high enough to pose an exposure risk to humans, and if environmental resistant bacteria are transmitted to humans and threaten public health remains and is a key consideration for policy-makers around the world.

There has been relatively little evidence synthesis work on environmental AMR. One recent systematic review investigated what was the most effective control measure in preventing the dissemination of AMR in the environment [42]. This work, however, did not investigate the potential exposure and transmission of environmental AMR to humans. To the best of the authors' knowledge, there has not been any evidence synthesis work investigating this.

The aim of this article is to provide a systematic map protocol. Here we are following ROSES for systematic map protocol reporting standards (provided as an Additional file 1) and CEE guidance for methods.

\section{Stakeholder engagement}

Initial revising of the scope of the question for the two maps was undertaken through a meeting with a member from the Environment Agency.

Subsequently, a number of stakeholders were asked to make comments on the inclusion and exclusion criteria, search terms and sources of grey literature via email. These stakeholders were from: Animal and Plant Health Agency; AstraZeneca; Centre for Environment, Fisheries and Aquaculture Science; Department for Environmental, Food \& Rural Affairs; Environment Agency; Food Standards Agency; Joint Nature Conservation Committee; Public Health England; Severn Trent Water and Veterinary Medicines Directorate.

A further meeting was held to further discuss sources of grey literature searching, outputs of the maps that stakeholders would find most useful and potential means of dissemination of the outputs through stakeholder organisations using directed questions. This was attended by members from organisations mentioned above, in addition to: Department of Agriculture, Environment and Rural Affairs; GlaxoSmithKline; Public Health England; Royal Devon \& Exeter Hospital Trust; Severn Trent Water; Welsh Government and Wessex Water.

Finally, stakeholders will be consulted to discuss preliminary findings, to ensure that outputs are meaningful to specific organisations and that key gaps and gluts of evidence are prioritised for the maps. Outputs will not exclusively be those which are suggested by stakeholders and suggestions from stakeholders will be discussed by the team to ensure non-biased outputs whilst encompassing stakeholder suggestions and priorities. These discussions were originally planned to be undertaken as another formal meeting. As a result of the global pandemic this will now take place via informal means such as email, virtual meetings and/or telephone interviews.

\section{Objective of review}

The aim is to conduct systematic mapping exercise in order to provide data on current evidence and identify research gluts and gaps relating to AMR in the environment and whether this can affect human health.

Primary research question: What research evidence is there that humans are exposed to and affected by AMR in the environment?

This will be broken down into two evidence maps:

Map 1: What research evidence is there about $A R B$ exposure and transmission to humans from the environment?

This will include studies that investigate either measureable health outcomes (e.g. colonisation, infection or mortality) or an estimated exposure risk in humans via direct contact such as inhalation or consumption from antibiotic resistant bacteria from environmental sources (e.g. water or soil sources).

Map 2: What research evidence is there measuring the prevalence of ARB in the environment in the UK? This will be UK based as the funding's remit is for UK policy based research. This will help to elucidate which environments have been extensively researched and which are currently under researched.

This will include studies that investigate the prevalence, percentage or abundance of resistant bacteria in environments such as various water environments and soil environments for example.

\section{Methods \\ Searching for articles}

Medline via OvidSP has been used to develop and refine the bibliographic database searches for both maps by the information specialist $(\mathrm{AB})$ through a process of scoping, checking against a list of known includable papers and with the project team. Both free text terms and controlled vocabulary terms were used when available and relevant. This search will be translated across the following databases:

Medline (1946-present), CAB Abstracts (1973-present), Global Health (via OvidSP, 1973-present), BIOSIS Citation Index (1969-present), Web of Science Core Collection (via Web of Science, 1900-present), GreenFILE, Environment Complete (via EBSCOhost, 1888-present), 
SCOPUS (1788-present), Epistemonikos, ProQuest Dissertations and Theses Global (via ProQuest, 1637-present), Explore (via the British Library), and AGRIS (via FAO). Please note that these databases will be limited by a search date (details can be found below).

All the results for both maps will be downloaded into Endnote X8 where duplicates will be removed. Supplementary search methods will be used for both maps to attempt to capture additional relevant information including forwards and backwards citation searching of included articles, hand searching of relevant journals and searching within organisational websites.

The Medline search string for both maps can be found in an Additional file 2 (Medline search strategy).

For Map 2:

To focus searches to geographically relevant studies, a modified version of the MEDLINE Ovid UK search filter [43] will be used for all the bibliographic database searches in Map 2.

Key author searches on both Web of Science Core Collection and SCOPUS will be run for Gaze, W. Wellington, E. and Amos, GC. These authors were chosen based on expert advice as key people working and publishing in this field in the UK. These results will be added to the other database search results.

Google scholar searches will also be carried out using a simplified search string with the first 1000 hits being downloaded. We will search google scholar using the Publish or Perish software using the following two strings: "Antimicrobial resistance and UK" and "Antimicrobial resistance and United Kingdom" both just in the title. These results will be added to the other search results.

The following websites will be searched:

Cefas (Centre for Environment, Fisheries and Aquaculture Science)

EA (Environment Agency)

SEPA (Scottish Environmental Protection Agency)

Defra (Department of Environment, Food and Rural Affairs)

APHA (Animal and Plant Health Agency)

VMD (Veterinary Medicines Directorate)

PHE (Public Health England)

CARS (Control of Antimicrobial Resistance Scotland)

HPS (Health Protection Scotland)

Welsh government

\section{Limits}

For both maps, only studies published in English will be considered due to limited resources and as this is relevant to UK policy scenarios for Map 2. Map 1 will be date limited to evidence published from 2009 and Map 2 date limited to 2005.

\section{Estimating the comprehensiveness of the search}

The comprehensiveness of both of the maps have been tested by using key papers that were known to be included after full text screening to validate that the searches were identifying these. For Map 1, 11 publications were used and for Map 2, 8 publications were used. A list of these references for both maps can be found as an Additional file 3 (Key papers). The final searches were able to identify all key papers for both questions.

\section{Search update}

The searches will not be updated prior to publication as this is a short term project. It is expected that the results of this systematic mapping exercise will be available within a year of the search date.

\section{Article screening and study eligibility criteria Screening strategy}

Studies retrieved from the searches will be imported into EndNote, duplicates will be removed and articles will be screened in two stages. An initial screening of 100 articles will be undertaken at title and abstract stage and discussion of all will occur between reviewers to ensure consistency. Titles and abstracts will be screened against the inclusion and exclusion criteria by one reviewer (as a result of resource constraints), with at least $10 \%$ of results being screened by a second reviewer to ensure consistency. Kappa coefficient will be used to evaluate consistency between the two reviewers. The kappa coefficient will be used as a guide and if the score is equal to or below 0.6 , this will prompt discussion points, refining of the eligibility criteria and a further evaluation of 100 articles will be undertaken and discussions will occur. In addition, all discrepancies will be discussed by the two reviewers and the wider review team will be consulted if necessary. At the second stage, full texts identified in the first screening will be assessed for their eligibility with one reviewer screening and extracting meta-data from all articles (as a result of resource constraints) and a minimum of $10 \%$ being screened and extracted by a second reviewer. Reviewers that have authored papers which are found during the searching process will not review these publications to avoid biases towards these publications. These papers will be screened at both abstract and title screening and full text screening by an impartial reviewer.

A list of studies that are excluded at full text screening will be made available with reasons for exclusion.

\section{Eligibility criteria \\ Map 1}

Details of the eligibility criteria and justifications for these are presented in Table 1. The question is expressed in a PEO format (Population, Exposure, Outcome) with 


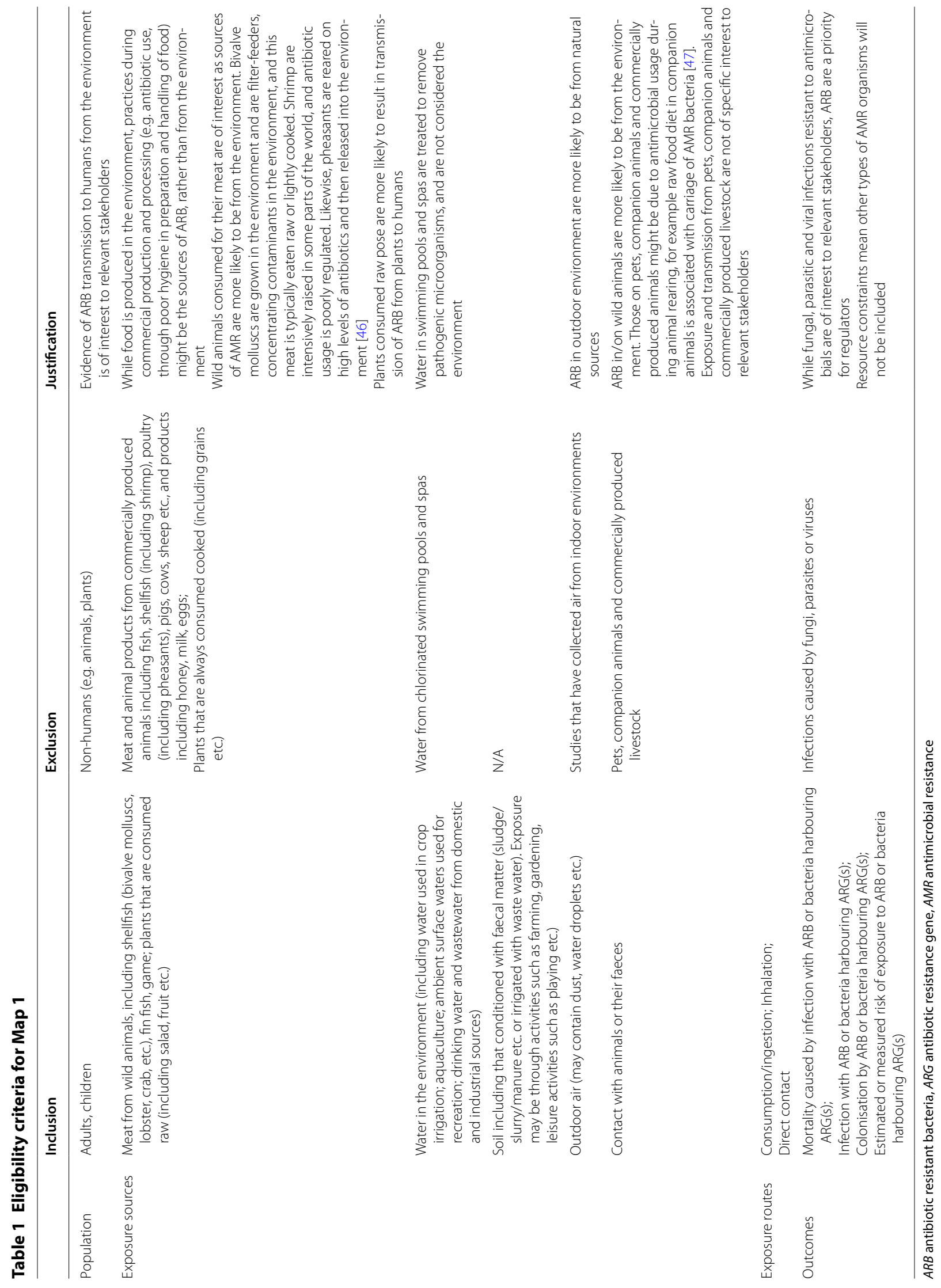


Table 2 Eligibility criteria for Map 2

\begin{tabular}{|c|c|c|c|}
\hline & Inclusion & Exclusion & Justification \\
\hline Population & Bacteria & Fungi, parasites, viruses & $\begin{array}{l}\text { ARBs are a priority interest for relevant stakeholders. Resource } \\
\text { constraints mean other types of AMR organisms will not be } \\
\text { included }\end{array}$ \\
\hline Exposure sources & As in Table 1 & As in Table 1 & As in Table 1 \\
\hline Exposure routes & Exposure to AMR organisms & & \\
\hline Outcomes & $\begin{array}{l}\text { Prevalence/percentage of ARB } \\
\text { Prevalence/percentage of ARGs }\end{array}$ & $\begin{array}{l}\text { Presence of } A R B / A R G s \\
\text { with no quantification }\end{array}$ & \\
\hline
\end{tabular}

$A R B$ antibiotic resistant bacteria, $A R G$ antibiotic resistance gene, $A M R$ antimicrobial resistance

the exposure sources and routes both considered important for this question.

\section{Map 2}

Details of the eligibility criteria justifications for these are presented in Table 2. The question is expressed in a PEO format (Population, Exposure, Outcome) with the exposure sources and routes both considered important for this question.

\section{Relevant types of study}

Studies will be commercially published work and grey literature. For Map 1, these studies will include systematic reviews, experimental studies (randomised exposure trials), observational studies (prospective/retrospective cohort studies, cross-sectional studies, case studies and case series) and modelling studies (for example quantitative microbial risk assessments). For Map 2, relevant study types will include systematic reviews and environmental surveillance studies.

\section{Location}

Whilst Map 1 will not include geographic limitations on study location, Map 2 will be restricted to only include studies where data is available from locations in the United Kingdom. There are expected to be many more eligible studies for Map 2 than for Map 1, and due to limited resources, data pertinent to the UK has been prioritised so that this map will be of most use to UK based policy makers and stakeholders.

\section{Date range}

For Map 1, literature published in the past 10 years (from 2009) will be included. Older studies will be excluded, but eligible research prior to this date is unlikely. For Map 2, searching will be extended to include studies published between 2005 and the present, as this is when interest in the topic of AMR in the environment started to increase. These dates have been selected based on advice from experts in the field.

\section{Study validity assessment}

No formal validity appraisal of included studies will be performed. However, study designs of included studies will be extracted for the maps.

\section{Data coding strategy}

For both of the maps we will extract the following metadata: bibliographic information; study location; study type; exposure source (main category-water, food, air, sediment, soil, animal faeces); exposure source (sub-categories. For example-Water: coastal, river, lake, groundwater, wastewater treatment plant influent, wastewater treatment plant effluent, drinking, crop irrigation etc.); whether there was a comparator and outcome.

For Map 1, information on population types and exposure route will also be extracted.

For Map 2, information about the experimental methodology used will also be extracted.

\section{Study mapping and presentation}

We will follow ROSES guidance for reporting on the systematic maps [44]. As well as the narrative synthesis of the systematic maps, data collected from the eligible studies will be recorded in an Excel spreadsheet and made available as an additional file. Both maps will be presented using the EviAtlas tool and will be uploaded online [45]. We plan to display: the location of the studies; heatmaps showing different exposure sources or routes by different outcome measures and details of the impact to relevant populations.

\section{Supplementary information}

Supplementary information accompanies this paper at https://doi. org/10.1186/s13750-020-00197-6.

Additional file 1. ROSES for Systematic Map Protocols checklist.

Additional file 2. Medline search strategy.

Additional file 3. Key papers for validating the search strategy. 


\section{Acknowledgements}

We would like to thank stakeholders who have engaged with us for their valuable contribution to defining the scope of this work.

\section{Authors' contributions}

$A L, W G, R G$ conceived of the project. IS, AL, WG and RG developed the inclusion/exclusion criteria. AB developed the search terms and strings. AB wrote the draft manuscript sections related to the searching. IS wrote the draft of all other sections. All authors read and revised the drafted manuscript. All authors read and approved the final manuscript.

\section{Funding}

This work is funded by the Natural Environment Research Council (NERC) Environmental Evidence for the Future (EEF) Grant (NE/S015965/1). AL is supported by a NERC Industrial Innovation Fellowship Grant (NE/R013748/1).

\section{Availability of data and materials}

Not applicable

\section{Ethics approval and consent to participate}

Not applicable.

\section{Consent for publication}

Not applicable.

\section{Competing interests}

The authors declare that they have no competing financial interests.

\section{Author details}

${ }^{1}$ European Centre for Environment and Human Health, College of Medicine and Health, Penryn Campus, University of Exeter, Penryn TR10 9FE, UK. ${ }^{2}$ College of Medicine and Health, St Luke's Campus, University of Exeter, Exeter EX1 1TX, UK. ${ }^{3}$ European Centre for Environment and Human Health, College of Medicine and Health, Knowledge Spa, University of Exeter, Truro TR1 3HD, UK.

Received: 1 April 2020 Accepted: 25 May 2020

Published online: 03 June 2020

\section{References}

1. Livermore DM. Has the era of untreatable infections arrived? J Antimicrob Chemother. 2009;64:29-36.

2. O'Neill J. Antimicrobial resistance: tackling a crisis for the health and wealth of nations. Rev Antimicrob Resist. 2014;20:1-16. https://amr-revie w.org/sites/default/files/AMR\%20Review\%20Paper\%20-\%20Tackling \%20a\%20crisis\%20for\%20the\%20health\%20and\%20wealth\%20of\%20nat ions_1.pdf.

3. Cabinet Office. National Risk Register of Civil Emergencies 2015 edition. 2015.

4. Cabinet Office. National Risk Register of Civil Emergencies 2017 edition. 2017.

5. Finley RL, Collignon P, Larsson DG, McEwen SA, Li XZ, Gaze WH, et al. The scourge of antibiotic resistance: the important role of the environment. Clin Infect Dis. 2013;57(5):704-10.

6. Wellington EM, Boxall AB, Cross P, Feil EJ, Gaze WH, Hawkey PM, et al. The role of the natural environment in the emergence of antibiotic resistance in gram-negative bacteria. Lancet Infect Dis. 2013;13(2):155-65.

7. Nhu NTK, Riordan DW, Nhu TDH, Thanh DP, Thwaites G, Lan NPH, et al. The induction and identification of novel Colistin resistance mutations in Acinetobacter baumannii and their implications. Sci Rep. 2016;6:1-8.

8. O'Neill J. Securing new drugs for future generations: the pipeline of antibiotics. Rev Antimicrob Resist. 2015;1-41.

9. Gupta SK, Nayak RP. Dry antibiotic pipeline: regulatory bottlenecks and regulatory reforms. J Pharmacol Pharmacother. 2014;5(1):4-7.

10. WHO. Antimicrobial resistance. Bull World Health Organ. 2014;61(3):383-94.

11. O'Dowd A. Death certificates should record antimicrobial resistance as cause of deaths, says CMO. BMJ. 2018:362:k3832
12. Singer AC, Shaw $H$, Rhodes $V$, Hart A. Review of antimicrobial resistance in the environment and its relevance to environmental regulators. Front Microbiol. 2016;7:1728

13. De Francesco V, Giorgio F, Hassan C, Manes G, Vannella L, Panella C, et al. Worldwide H. pylori antibiotic resistance: a systematic review. J Gastrointestin Liver Dis. 2010;19(4):409-14.

14. Bell BG, Schellevis F, Stobberingh E, Goossens H, Pringle M. A systematic review and meta-analysis of the effects of antibiotic consumption on antibiotic resistance. BMC Infect Dis. 2014;14:13.

15. Fridkin SK, Steward CD, Edwards JR, Pryor ER, McGowan JE Jr, Archibald LK, et al. Surveillance of antimicrobial use and antimicrobial resistance in United States hospitals: project ICARE phase 2. Project Intensive Care Antimicrobial Resistance Epidemiology (ICARE) hospitals. Clin Infect Dis. 1999:29(2):245-52.

16. Obritsch MD, Fish DN, MacLaren R, Jung R. National surveillance of antimicrobial resistance in Pseudomonas aeruginosa isolates obtained from intensive care unit patients from 1993 to 2002. Antimicrob Agents Chemother. 2004:48(12):4606-10.

17. Kumari M, Batra P, Malhotra R, Mathur P. A 5-year surveillance on antimicrobial resistance of Acinetobacter isolates at a level-I trauma centre of India. J Lab Physicians. 2019;11(1):34-8.

18. Gaze WH, Depledge M. Antimicrobial resistance: investigating the environmental dimension. Frontiers 2017: Emerging Issues of Environmental Concern. United Nations Environment Programme. 2017:12-22. https://wedocs.unep.org/handle/20.500.11822/22263?show=full.

19. D'Costa VM, King CE, Kalan L, Morar M, Sung WWL, Schwarz C, et al. Antibiotic resistance is ancient. Nature. 2011:477(7365):457-61.

20. Holmes AH, Moore LSP, Sundsfjord A, Steinbakk M, Regmi S, Karkey A, et al. Understanding the mechanisms and drivers of antimicrobial resistance. Lancet. 2016;387(10014):176-87.

21. Levison ME, Levison JH. Pharmacokinetics and pharmacodynamics of antibacterial agents. Infect Dis Clin N Am. 2009;23(4):791-815.

22. Andersson DI, Hughes D. Evolution of antibiotic resistance at nonlethal drug concentrations. Drug Resist Update. 2012;15(3):162-72.

23. Murray AK, Zhang L, Yin X, Zhang T, Buckling A, Snape J, et al. Novel insights into selection for antibiotic resistance in complex microbial communities. mBio. 2018;9(4):e00969-18.

24. Lundstrom SV, Ostman M, Bengtsson-Palme J, Rutgersson C, Thoudal M, Sircar T, et al. Minimal selective concentrations of tetracycline in complex aquatic bacterial biofilms. Sci Total Environ. 2016;553:587-95.

25. Kraupner N, Ebmeyer S, Bengtsson-Palme J, Fick J, Kristiansson E, Flach CF, et al. Selective concentration for ciprofloxacin resistance in Escherichia coli grown in complex aquatic bacterial biofilms. Environ Int. 2018;116:255-68.

26. Gullberg E, Albrecht LM, Karlsson C, Sandegren L, Andersson DI. Selection of a multidrug resistance plasmid by sublethal levels of antibiotics and heavy metals. mBio. 2014;5(5):e01918-14.

27. Gullberg E, Cao S, Berg OG, Ilback C, Sandegren L, Hughes D, et al. Selection of resistant bacteria at very low antibiotic concentrations. PLoS Pathog. 2011;7(7):e1002158.

28. Canton R, Jose MGA, Galan JC. CTX-M enzymes: origin and diffusion. Front Microbiol. 2012;3:110.

29. Ashbolt NJ, Amezquita A, Backhaus T, Borriello P, Brandt KK, Collignon P, et al. Human Health Risk Assessment (HHRA) for environmental development and transfer of antibiotic resistance. Environ Health Perspect. 2013;121(9):993-1001.

30. Leonard AFC, Zhang L, Balfour AJ, Garside R, Hawkey PM, Murray AK, et al. Exposure to and colonisation by antibiotic-resistant E. coli in UK coastal water users: environmental surveillance, exposure assessment, and epidemiological study (Beach Bum Survey). Environ Int. 2018;114:326-33.

31. Leonard AFC. Are bacteria in the coastal zone a threat to human health? [Thesis]. University of Exeter; 2016.

32. Morris GP, Beck SA, Hanlon P, Robertson R. Getting strategic about the environment and health. Public Health. 2006;120(10):889-903 (discussion-7).

33. Hirsch R, Ternes TA, Haberer K, Mehlich A, Ballwanz F, Kratz K. Determination of antibiotics in different water compartments via liquid chromatography-electrospray tandem mass spectrometry. J Chromatogr A. 1998;815(2):213-23 
34. Kostich MS, Batt AL, Lazorchak JM. Concentrations of prioritized pharmaceuticals in effluents from 50 large wastewater treatment plants in the US and implications for risk estimation. Environ Pollut. 2014;184:354-9.

35. Boxall AB, Blackwell P, Cavallo R, Kay P, Tolls J. The sorption and transport of a sulphonamide antibiotic in soil systems. Toxicol Lett. 2002;131(1-2):19-28.

36. Armstrong JL, Shigeno DS, Calomiris JJ, Seidler RJ. Antibiotic-resistant bacteria in drinking water. Appl Environ Microbiol. 1981;42(2):277-83.

37. Schwartz T, Kohnen W, Jansen B, Obst U. Detection of antibiotic-resistant bacteria and their resistance genes in wastewater, surface water, and drinking water biofilms. FEMS Microbiol Ecol. 2003;43(3):325-35.

38. Boehme S, Werner G, Klare I, Reissbrodt R, Witte W. Occurrence of antibiotic-resistant enterobacteria in agricultural foodstuffs. Mol Nutr Food Res. 2004:48(7):522-31.

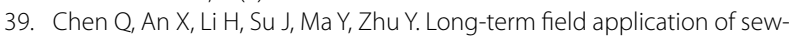
age sludge increases the abundance of antibiotic resistance genes in soil. Environ Int. 2016;92-93:1-10.

40. Marti R, Scott A, Tien Y, Murray R, Sabourin L, Zhang Y, et al. Impact of manure fertilization on the abundance of antibiotic-resistant bacteria and frequency of detection of antibiotic resistance genes in soil and on vegetables at harvest. Appl Environ Microbiol. 2013;79(18):5701-9.

41. Zhang $X X$, Zhang T, Fang $\mathrm{HH}$. Antibiotic resistance genes in water environment. Appl Microbiol Biotechnol. 2009;82(3):397-414.

42. Goulas A, Belhadi D, Descamps A, Andremont A, Benoit P, Courtois S, et al. How effective are strategies to control the dissemination of antibiotic resistance in the environment? A systematic review. Environ Evid. 2020;9(4):1-32.

43. Ayiku L, Levay P, Hudson T, Craven J, Barrett E, Finnegan A, et al. The medline UK filter: development and validation of a geographic search filter to retrieve research about the UK from OVID medline. Health Info Libr J. 2017;34(3):200-16.

44. Haddaway NR, Macura B, Whaley P, Pullin AS. ROSES RepOrting standards for Systematic Evidence Syntheses: pro forma, flow-diagram and descriptive summary of the plan and conduct of environmental systematic reviews and systematic maps. Environ Evid. 2018;7:7.

45. Haddaway NR, Feierman A, Grainger MJ, Gray CT, Tanriver-Ayder E, Dhaubanjar S, et al. EviAtlas: a tool for visualising evidence synthesis databases. Environ Evid. 2019;8(1):22.

46. Madden JR, Hall A, Whiteside MA. Why do many pheasants released in the UK die, and how can we best reduce their natural mortality? Eur J Wildlife Res. 2018;64(4):40.

47. Nuesch-Inderbinen M, Treier A, Zurfluh K, Stephan R. Raw meat-based diets for companion animals: a potential source of transmission of pathogenic and antimicrobial-resistant Enterobacteriaceae. R Soc Open Sci. 2019;6(10):191170.

\section{Publisher's Note}

Springer Nature remains neutral with regard to jurisdictional claims in published maps and institutional affiliations.
Ready to submit your research? Choose BMC and benefit from:

- fast, convenient online submission

- thorough peer review by experienced researchers in your field

- rapid publication on acceptance

- support for research data, including large and complex data types

- gold Open Access which fosters wider collaboration and increased citations

- maximum visibility for your research: over $100 \mathrm{M}$ website views per year

At BMC, research is always in progress.

Learn more biomedcentral.com/submissions 